\title{
Reflecting on knowledge management as an enabler of innovation in project-based construction firms
}

Purpose - This article explores the ways innovation becomes enabled through knowledge management and sharing which has important implications for establishing and sustaining the culture of innovative thinking in project-based construction firms. We adopt reflective practitioner perspective in order to explore this relationship.

Design/methodology/approach - Thirty semi-structured interviews were conducted with the construction sector professionals whose rules are most relevant in the connection between innovation and knowledge management. Thematic analysis and cognitive mapping technique were used to analyse the interview data.

Findings - The research findings indicate that due to the complexity of project-based construction firms a more holistic approach to knowledge management and organisational learning at the firm level is required. This would enable a culture of continuous and coordinated knowledge flow that facilitates innovation and continuous improvement in project-based firms.

Practical implications - This article has important implications for practising managers in project-based construction firms. By better understanding the ways organisational knowledge can be managed to become an enabler of innovation would allow to build and enhance firms' innovative capabilities, individual and team competencies. There is a real need for innovation knowledge managers as formal job positions in the construction sector.

Originality/value - This article contributes to construction innovation and project management research and practice by providing insights into establishing and sustaining the culture of learning and innovative thinking.

Keywords Knowledge management, innovation management, culture of learning and innovative thinking, reflective practitioner, project-based construction firms.

Paper type: Research Paper

\section{Introduction}

The capability to innovate depends largely on the way in which an organisation uses and exploits the knowledge and expertise of its employees (e.g. Anumba et al., 2005; Newell et 
al., 2009). Contemporary organisations have realised that their competitiveness depends on acceleration of innovation and knowledge flow. The importance of innovation and knowledge management (IM \& KM) as ultimate competitive advantages for project-based organisations has been increasingly recognised by both academics and practitioners (e.g. Blayse and Manley, 2004; Bossink, 2004; Carrillo et al., 2000; Gann and Salter, 1998, 2000). Projectbased firms (PBFs) generate a great deal of context-specific tacit knowledge which is a product of experience and innovative problem solving (e.g. Kelly et al., 2013). PBFs invest in mechanisms that allow them to capture the experience gained from projects (Prencipe and Tell, 2001), however, the potential of knowledge management is not yet fully recognised as an enabler for facilitating and sustaining innovation (Walker, 2016).

The construction sector is criticized for lack of innovation and challenges to share knowledge in comparisons to other sectors (McKinsey Global Institute, 2017). In PBFs employees constantly move from one project to another and work with different organisations across supply chains (e.g. Blayse and Manley, 2004, 2018; Carrillo et al., 2000). Much of the tacit knowledge in the sector resides in the heads of individuals and is mainly transferred through informal channels. If knowledge from projects is not maintained, then it will be lost when a project is completed. At the same time, even when knowledge is maintained and stored in a knowledge repository, there is a little chance that the other projects will learn from it, and there is a little room for innovation. In order to learn and innovate on projects, robust KM and IM processes are needed in PBFs (e.g. Duryan and Smyth, 2019a; Payne et al., 2019). Considering the intangible nature of knowledge, it cannot be directly managed without the environment that encourages learning from success and failure of innovation. This creates challenges but also opportunities for improving $\mathrm{KM}$ practices that have important implications for enabling, sustaining and accelerating innovation. In this article we emphasise this and also demonstrate the impact of connectivity between KM and IM for sustaining the culture of innovative thinking. The construction sector provides particularly rich settings to 
explore KM as an enabler of innovation in PBFs (Egbu, 2004; Maqsood and Finegan, 2009). We adopt Schön's (1983) reflective practitioner perspective in order to explore practitioners' own perceptions on the connectivity between $\mathrm{KM}$ and IM. This perspective allows us to explore reflections of experienced innovation knowledge managers and their vision for the future actions.

\section{KM and IM in project-based environments}

Knowledge sharing and learning serve as a basis for innovation in PBFs (Artto and Kujala, 2008; Gann and Salter, 1998). They must continuously generate new knowledge and skills to retain their competitive advantage. There is agreement among the researchers that the construction industry is slow to innovate and learn (e.g. Atkin, 1999; Barlow, 2000; Flyvbjerg et al., 2002; Hertogh et al., 2008). Despite many research papers on IM and KM, there are still challenges in capturing and transferring knowledge to enable innovation in PBFs (Gann and Salter, 2000; Love et al., 2005). The firms develop a tendency to "reinvent the wheel" when faced with similar problems in existing and new projects (Gann and Salter, 2000). The question remains as to how firms in project-based sector can overcome some of the main obstacles to knowledge sharing in individual, cultural and technological domains to cultivate a culture of innovative thinking and learning.

The construction industry is often seen as knowledge-intensive, considering a high level of expert knowledge and know-how required to solve problems (Castro et al., 2012; Carrillo, 2004; Dave and Koskela, 2009). Complex and ill-defined problems require innovation and problem-solving competencies drawing upon an organisational knowledge base (Ruoslahti, 2020). However, temporary and diverse nature of the projects, pressure to complete and lack of incentive to improve project delivery make it difficult to create a culture of continuous innovation and knowledge flowing system. This is particularly critical considering that the processes and products of PBFs are often more unique and design-driven (Gann and Salter, 
2000; Hobday, 2000; Turner and Keegan, 2001) and the tacit form of knowledge is predominant due to the non-repetitive nature of much project work (Kelly et al., 2013; Szulanski, 2000). Besides, project team members in PBFs, especially in the construction industry, bring expertise and innovative problem solving from other firms in order to deliver their own technical and social capabilities (Kelly et al., 2013). Maqsood and Finegan (2009) investigated the role of KM in supporting innovation and learning in the construction industry and found the importance of integration of three components in an organisation - people, process and technology. The improvements in the integration of these help an organisation to transform itself into a learning organisation which continuously adapt and innovate.

At the end of each project, employees are often moved on to the next project before the analysis of lessons learned from past experiences. The pressure on employees to deliver the project on time and within the budget prevents them from making the necessary effort to meet and share the knowledge and experiences produced by previous projects (Love et al., 2005). As a result, knowledge and lessons learned are dispersed and not captured deleting the organisation's knowledge, which creates barriers to learning and reusing knowledge in future projects and often leads to poor performance (Gann and Salter, 2000; Castro et al., 2012; Train et al., 2006). Thus, there is more urgent need for PBFs to integrate both project- and business processes to be able to capitalise on knowledge generated from projects and enhance the firm's innovative capabilities (Gann and Salter, 2000; Saunila, 2019).

For PBFs to capitalise on the "know-how" acquired in previous and current projects they need to manage knowledge more holistically and purposefully, combining techniques from executive management, human resource management, $\mathrm{KM}$ and IM disciplines themselves (Egbu, 2004; Davenport and Prusak, 1998). The organisations do not have to reinvent the wheel every time they start a new project if the lessons learnt are systematically incorporated into organisational standards and processes and are shared with all stakeholders involved in projects (Carrillo et al., 2013; Castro et al., 2012; Dave and Koskela, 2009). 
PBFs are fundamentally about innovation and learning, whether the projects these firms deliver are about setting out to advance technology, or whether they seek to combine existing technologies is a novel way to meet the client's business case (Davies et al., 2009; Davies et al., 2017). Collective practice, learning and innovating are different facets of each other. Innovations can only be done collaboratively across client and supplier firms and people there within, and orchestrating such collaboration is one of the great challenges of project organising (Winch, 2014). It is hence critical to understand how PBFs build and enhance their IM and KM capabilities, as well as how they establish and sustain a culture of innovative thinking and learning.

\section{The culture of learning and innovative thinking}

Effective verbal and written communication is fundamental to constructive knowledge sharing (e.g. Davenport and Prusak, 1998). At the same time, the attempts to transform and share or transfer existing knowledge may not be always successful due to established habits and routines, organisational politics, silo mentality, the tensions within hierarchies and lack of leadership support, among other things. The main challenge for any organisation still remains cultivation of a culture that will enable double- and triple-loop thinking, reflection on practices and lessons learnt and innovation.

Cultivating an organisational culture that encourages knowledge sharing has been identified as one of the most important aspects contributing to success of IM and KM initiatives (e.g. Davenport and Prusak, 1998; De Long and Fahey, 2000; Ruggles, 1998). Organisational culture is considered as shared system of values and beliefs which become manifest in the behaviour and actions of organisational members (Hartmann, 2006). An organisations culture either promotes learning and innovation, or hinders it through stimulating defensive tendencies or individualistic behaviour among the workforce (De Long and Fahey, 2000). 
One of the commonly accepted barriers to learning and knowledge sharing is the broad scope of large construction projects that requires input from different organisations that are more concerned with pursuing their own interests rather than cultivating a culture of knowledge sharing (Train et al., 2006). Another barrier to effective IM and KM in large construction firms is seen a lack of senior management support (Carillo, 2013; Duryan and Smyth, 2019b). A culture of innovation, learning and knowledge exchange is understood as where people are encouraged to work together, to collaborate and share, and be rewarded for doing so. There is a tendency in PBFs to rely on the collection of data and IT depositories. IT systems and software platforms can support knowledge sharing and application, however merely establishing IM and KM system does not automatically generate high engagement levels, a learning environment or lead to a greater understanding. PBFs need to focus on human systems, where innovation and knowledge resides (Churchman, 1972; Blackman, 2005).

Blayse and Manley (2004) recognise that construction industry practitioners, their relationships and collaborations play an important role in facilitating knowledge flow and encouraging innovation. Following a human-oriented approach to IM and KM, we need to pay greater attention to joint experience and interaction in social networks (Bossink, 2018; Newell et al., 2006). Lave and Wenger (1991) followed a "social" view of learning and developed the concept of communities of practice, where more experienced members can share their tacit knowledge with less experienced colleagues. Communities of practice can become risk-free loosely coupled operating systems that can encourage organisational innovation and learning across different functional and project boundaries and can boost creativity and effective problem solving (Duryan and Smyth, 2019a). Dulami et al. (2005) found that, on average, a supportive culture or climate fosters innovation championing behaviour, from the project managers' perspectives. There is a recognition that innovation champions play an important role in facilitating IM and $\mathrm{KM}$ practices and contribute to 
creating a culture of learning and innovative thinking in PBFs (e.g. Blayse and Manley, 2004; Egbu, 2004). In order to better understand the ways KM enables innovation in PBFs we draw from the broader IM and KM literature and adopt Schön's (1983) reflective practitioner perspective.

\section{Innovation management}

The most commonly accepted definition of innovation is the development and implementation of new ideas by people who over time engage in transactions with others within an institutional order (Van de Ven, 1986; Van de Ven et al., 2008). Innovation can be a new product, process or service that has a step change and creates value, e.g. economic value, environmental value, societal value etc. (Prahalad and Ramaswamy, 2003; Ruoslahti, 2020). It may be new to a firm but not necessarily new to the world. Innovation also entails the application of knowledge to new tasks and situations in order to develop new products, processes and services, and is a prime site for "knowledge work" (Du Plessis, 2007; Newell et al., 2009). IM is often defined as the embodiment and synthesis of knowledge in original, relevant and valued new products, processes or services (Barbaroux et al., 2016). According to Van de Ven (2017, p. 39):

"Managers and entrepreneurs can increase their odds of success by developing and practicing skills in learning, leading, relating, and cycling through the innovation journey."

During the innovation journey, managers are argued to increase their opportunities for success by developing and practising skills in key processes such as leading, learning, relating and cycling. In PBFs, innovation leaders aim to succeed and learn from innovation successes (as well as failures). Van de Ven (2017) calls for further process studies of how innovation journey unfolds from concept to development and implementation in different organisational settings. The chances to succeed in the innovation journey depend on the successes of 
developing and practising skills in $\mathrm{KM}$ and learning by managers and employees in organisations.

\section{Knowledge management}

\section{Tacit and explicit knowledge}

Nonaka and Takeuchi (1995, p. 58) define knowledge as "a meaningful set of information". They emphasise the importance of continuous creation and application of knowledge for the organisations to foster innovation. Based on the work of Polanyi $(1962,1967)$, there are two dimensions of knowledge in organisations: tacit and explicit. The notion of tacit knowledge was first coined by Polanyi (1962) as very personal, difficult to codify or document, and is often the result of organisational or individual experience. The main issue with tacit knowledge is that not only the receiver may misinterpret what the sender is trying to convey, but also the sender may be unable to fully articulate the true or full nature of the information s/he is disclosing because "we know more than we can tell" (Polanyi, 1962, p.4). The explicit dimension of knowledge can be codified, stored and communicated in formalised forms (e.g. documents, processes, frameworks, databases). According to Polanyi (1967) knowledge exists along a continuum between tacit knowledge and explicit knowledge.

\section{Knowledge management and sharing}

According to Ruggles (1998) KM is a newly emerging, interdisciplinary business model that deals with all aspects of knowledge within the context of the firm, including innovation. He also emphasizes the role of organisational culture and practices in managing knowledge in firms. In order to ensure flexibility in reaction to continuously changing environment and to support continuous innovation, the firms need to learn how to leverage their knowledge assets (Newell et al., 2009). Innovations that are based on knowledge of employees are unique and so valuable to the organisation (Train et al., 2006). 
The relationship between organisational knowledge and competitive advantage is moderated by the company's ability to apply knowledge (Bij et al., 2003). Creating an atmosphere of thinking, learning and communicating with the employees improves organisational knowledge repositories, and so the organisation's ability to develop existing knowledge, innovate and sustain innovations. It is very difficult to transform tacit knowledge that is intangible and mainly resides in minds of employees and organisational routines (Polyani, 1962). At the same time, experience is embedded in practice, and 'tacit knowing' cannot be transformed and shared without reflection on practice.

\section{A reflective practitioner perspective}

To be effective and to be replicated, innovation requires an understanding of the context in which it came about. Reflective practice, which is an active process of thinking and learning is widely considered to be an important activity for professional development. According to Dewey (1910, p.6) who was the first to coin the term, reflective practice means "active, persistent and careful consideration of any belief or supposed form of knowledge in the light of the grounds that support it”. Schön's (1983) built on Dewey’ work by developing a slightly different view suggesting two levels of reflection: reflection-in-action and reflection-onaction. Reflection-in-action refers to thinking while acting, which involves observing situation and responding by doing things differently and approaching the topic or task from a different perspective. Reflection-on-action allows deeper thinking about a certain situation, when the responses are linked to the current understanding of theories and existing knowledge, experience and values. Schön (1983) also reinforced that reflection before action is especially important because it encourages people to think about what they intend to do and brings about change in their perspectives and understandings.

Practitioners with years of experience deal with specific situations often enough to accumulate practical knowledge and skills automatically. They often act without reflecting on their skills and experience (Schön, 1983). However, given today’s complex, uncertain and 
unstable work environments, professionals need to put efforts and learn new skills, which implies reflection on their knowing-in-practice. Schön (1983) posits that professionals need to think not only about what they are doing but also think while they are doing it. He draws an analogy with the musicians playing jazz. They all know the basic theme and, at the same time, they play their parts listening to one another to align their play and collectively create music "evolving their ways of doing it" (Schön, 1983, p. 56).

Oeij et al. (2017) posit that reflection and learning are closely related, linking the model of the reflective practitioner to the theory of organisational learning, which recognises single-, double- and triple-loop learning (Argyris and Schön, 1974). Argyris and Schön (1978) see organisational learning as a distinction between cognitive, double loop learning doing things differently, and behavioural, single-loop learning - doing things better. At a level of triple-loop learning, professionals 'learns-to-learn' and are capable of more instrumental, strategic thinking. Based on the findings of their research, Oeij et al. (2017, p. 18) came to conclusion that reflective practice is not always observable but can be seen in its effects, which can form a "subject for reflection and imitation by team members and thus offer an opportunity for learning and obtaining new knowledge-on-action”.

The reflective skills provide a basis for continuous professional development, encouraging the employee to think, reflect on their professional practice and lessons learnt and plan future actions the way to keep up with the ambiguity of challenges they face in today's complex and unstable environment. For innovation to occur, a desire and capabilities to transform and share existing knowledge are required. The outcomes of collective efforts in developing a regular habit of reflective practice can be obtaining organisational capabilities to not only learn faster but also to innovate.

\section{Methodology}

An interpretative methodology was used in this research to assess the role of knowledge management as enabler for innovation in the construction industry PBFs. The methodology 
considers value judgments and subjectivity provided in context. We followed the approach adopted by Newell et al. (2009) drawing mainly on research on innovation, which demonstrates that knowledge work depends mainly on the attitudes, behaviours and motivations of knowledge owners who undertake and manage it, rather than on the implementation of information systems. The researchers studied the actors' perceptions, taking into account that they inform future behaviour and actions of actors. Methodologically, interpretation has the benefit of not suggesting a singular theoretical approach to IM or KM. Prior theory informs the collection of empirical material and acts as a guide but does not provide a determined framework.

Thirty semi-structured interviews were conducted in order to explore managers' perceptions of innovation. The interviewees were practitioners whose roles are most relevant in the connection between innovation and knowledge management: innovation knowledge managers, R\&D managers, innovation managers, business improvement managers and others in senior positions) in the settings of UK construction industry PBFs. In consistence with Schön's (1983) theory, the researchers were interested in perceptions of practitioners on their experiences and practices. Anticipatory or reflection-before-action is especially important as it encourages them to think about what they intend to do before they actually do. Practitioners' reflections on experiences bring about a change in their perspectives and understandings. Examples of interview questions were formulated as: "How do you define innovation?", “Could you please share examples of innovations in your firm?”, “Could you please reflect on how do you practice innovation?", "To what extent do individuals play a role in shaping the context within which innovation can take place?", "Do past experiences influence present and future innovations?", "Could you please reflect on the extent to which you learn from innovation?", "Do you think it is increasingly important that an organisation has a culture of innovation?". 
The interviews were initially audio-taped and then fully transcribed. The analysis commenced with a detailed reading of the transcripts several times over, noticing and looking for patterns of shared meaning. The analysis of the interview transcripts involved coding the textual material, identifying one or more passages of text that, in some sense, exemplify the same theoretical idea. The identified themes were cross-referenced across the interviews. The main theme identified was the strong connection between IM and KM in the ways practising managers talked about their practices and experiences. The interview data were analysed using the cognitive mapping technique which allowed to explore the identified themes in greater details. Cognitive map $(\mathrm{CM})$ is the term used to refer to one's internal representation of the experienced world (Eden and Ackermann, 1998). It is a problem structuring method of the SODA (Strategic Options Development and Analysis) approach that has been developed through 'JOURNEY Making' (Jointly Understanding Reflecting and Negotiating strategy) (Eden and Ackermann, 1998). The idea of CM is based on Kelly's (1991) personal construct theory that aims at understanding of how people perceive their world by seeking to manage and control it (Eden, 2004). CM is a structured, two-dimensional directed graph that represents the issues from the perspectives of interviewees and visually demonstrates why a situation is problematic and what can (or cannot) be done about it (Eden, 2004). The links between the nodes demonstrate the implication (or causal) links among them and allow exploration of detailed and holistic properties (Eden and Ackermann, 1998). The objective of the analysis of the maps is to highlight the most important fields of concern from the perspectives of the key stakeholders. The content of a map can provide rich insights into the meaning of specific concepts and demonstrate the process of reflection on a specific issue. The technique helps mapping people's tacit knowledge about a certain problem without reducing the complexity. It allows seeing how the concepts mentioned by the participants are interrelated. 


\section{Discussion and Analysis}

The heads of a map, the concepts represented by the nodes that have only arrows going inside, demonstrate the goals expressed in terms of final ends or effects. The concept "improve organisational performance" is a head of the merged CM, which means that from the interviewees' perspectives, enhanced capabilities in IM and KM will lead to a better performance (Figure 1).

Domain (Table 1) and centrality (Table 2) analyses were used to identify the key issues in the models. Density of the direct links around the concepts helps in identifying best elaborated ones. The nodes with complex domain (high density) are considered to be the potential key issues from the perspectives of the interviewees (Eden, 2004). They can become the subjects for further examination.

The top 10 concepts for the merged map in descending order of value:

\section{Table 1 Domain analysis}

\section{DOMAIN ANALYSIS}

[Node 9] establish and sustain a culture of 17 links around innovative thinking...1 drive innovation through

"super-heroes"

[Node 1] enable innovation in construction 16 links around industry

[Node 16] share knowledge and experience 11 links around

[Node 2] improve knowledge management in

10 links around

\footnotetext{
1 "...", - rather then
} 
construction industry

[Node 21] cultivate a culture of learning

[Node 42] create a collaborative working

environment

[Node 33] choose clients who have the same

mindset regarding innovation

8 links around

[Node 65] capture knowledge

[Node 37] create environment where people are 7 links around

less risk averse

[Node 108] design innovation strategy 6 links around

[Node 14] consider multifacetedness of

organisational innovation

5 links around

[Node 30] ensure support from leadership

By analysing only the immediate domain of the concept by itself, we do not consider its wider context; hence, we needed to conduct centrality analysis. Centrality analysis (Table 2) extends the domain analysis by considering both, direct and indirect links. It reflects the downstream effect and allows a more accurate view of key issues than domain analysis (Ackermann and Eden, 2010). Centrality analysis measures the complexity of the concept's implication chain, considering that the greater the complexity, the more central is the concept. Concepts with the highest centrality scores usually strengthen the ideas expressed by concepts with the highest domain score. 


\section{CENTRALITY ANALYSIS}

\begin{tabular}{|c|c|}
\hline $\begin{array}{l}\text { [Node 1] enable innovation in construction } \\
\text { industry }\end{array}$ & $\begin{array}{l}50 \text { from } 103 \\
\text { concepts* }\end{array}$ \\
\hline $\begin{array}{l}\text { [Node 9] establish and sustain a culture of } \\
\text { innovative thinking ... drive innovation through } \\
\text { "super-heroes" }\end{array}$ & 49 from 97 concepts. \\
\hline [Node 21] cultivate a culture of learning & 42 from 87 concepts. \\
\hline $\begin{array}{l}\text { [Node 2] improve knowledge management in } \\
\text { construction industry }\end{array}$ & 38 from 84 concepts. \\
\hline $\begin{array}{l}\text { [Node 118] promote cultural 'openness' in } \\
\text { teams }\end{array}$ & 35 from 80 concepts. \\
\hline $\begin{array}{l}\text { [Node } 42] \text { create a collaborative working } \\
\text { environment }\end{array}$ & 35 from 75 concepts. \\
\hline [Node 30] ensure support from leadership & 34 from 78 concepts. \\
\hline $\begin{array}{l}\text { [Node 14] consider multifacetedness of } \\
\text { organisational innovation }\end{array}$ & 33 from 76 concepts. \\
\hline [Node 16] share knowledge and experience & 31 from 67 concepts. \\
\hline $\begin{array}{l}\text { [Node 101] look back and reflect on what has } \\
\text { been done to understand what was innovative }\end{array}$ & 30 from 71 concepts. \\
\hline [Node 37] create environment where people & 30 from 70 concepts. \\
\hline
\end{tabular}


are less risk averse

[Node 33] choose clients who have the same 30 from 64 concepts.

mindset regarding innovation

* for the Node 1 cent score is 50 and the total number of concepts traversed is 103 (max band number is 7)

Some concepts that were characterised by the highest domain score also have the highest centrality score. If a concept appears in both analyses, it means that it is both "locally and globally significant, confirming its position at the core of a potential key issue." (Ackermann and Eden, 1998, p. 405). Those concepts represent strategic directions (Table 3) that, from perspectives of the interviewees, contribute to achievement of the goal, which is "improve organisational performance" (Figure 1, node 22).

Table 3 Combined domain and centrality analysis

\section{CONCEPT}

[Node 1] enable innovation in construction industry

[Node 9] establish and sustain a culture of innovative thinking ... drive innovation through "super-heroes"

\begin{tabular}{lll}
\hline [Node 21] cultivate a culture of learning & 10 & 42 \\
\hline $\begin{array}{l}\text { [Node 2] improve knowledge management in } \\
\text { construction industry }\end{array}$ & 10 & 38 \\
\hline $\begin{array}{l}\text { [Node 42] create a collaborative working } \\
\text { environment }\end{array}$ & 10 & 35 \\
\hline $\begin{array}{l}\text { [Node 14] consider multifacetedness of } \\
\text { organisational innovation }\end{array}$ & 8 & 33 \\
\hline $\begin{array}{l}\text { [Node 16] share knowledge and experience } \\
\text { [Node 37] create environment where people } \\
\text { are less risk averse }\end{array}$ & 7 & 31 \\
\hline
\end{tabular}


According to the interviews the emergent issues (or strategic directions), in descending order of importance, are: 1) "enable innovation in the construction industry"; 2) "establish and sustain a culture of innovative thinking, rather than drive innovation through "super-heroes"; 3) "cultivate a culture of learning', 4) 'improve knowledge management in the construction industry"; 5) "create a collaborative working environment"; 6) "consider multifacetedness of organisational innovation"; 7) "share knowledge and experience" and 8) "create environment where people are less risk-averse" (Table 3).

An important enabler of innovation from the perspectives of the respondents is ability to reflect on what has been done (node 101), which helps practitioners to learn from past experience (node 20) to continuously develop reflective skills and enhance double- and tripleloop learning. That is aligned with what Argyris and Schön (1974) and Oeij et al. (2017) state on the importance of reflective skills for continuous professional development, ability to deal with the ambiguity of challenges and capabilities to learn faster. Based on the CM (Figure 1), the reflection-on-action (node 101) allows going through the lessons learnt or captured knowledge (node 65) to not only obtain new knowledge-on-action but also capture innovation (node 66).

The findings demonstrate that there is a shared understanding on the significance of the impact of IM and KM on organisational performance (Table 3, nodes 1 and 2). There was consensus among respondents that improvement in KM (node 2), cultivation of a learning culture (node 21), knowledge sharing (16) and learning from failures (node 36) will help to enable innovation in the construction industry. PBFs need to integrate both project- and business processes to retain and apply knowledge generated from projects to enhance the firm's innovative capabilities (Davies et al., 2009; Davies et al., 2017).

Majority of respondents emphasised the importance of sharing knowledge and experience. One of the interviewees, a Group Innovation and Knowledge Manager of a large 
construction contractor firm mentioned that it is important to create an environment where people are encouraged to learn about good practice:

"What is good practice here? What does it look like? How could we improve on that? What would we do differently? It is that mind-set. And because they [project members] are coming from different backgrounds, different experiences and different learning... they bring innovation into a way they think... We actually learned from failures"

A high level of expert knowledge that comes from the different organisations that take part in construction projects makes construction a knowledge-intensive sector that relies on professional knowledge or expertise relating to a specific technical or functional domain (Castro et al., 2012; Carrillo et al., 2013; Dave and Koskela, 2009). At the same time, the fragmented, temporary and unique nature of the projects creates obstacles for creating a culture of continuous knowledge flowing system. KM should be viewed as a process to make knowledge sharing "an integral part of the organisational work culture" (Duryan and Smyth, 2019b, p. 132).

There was a shared agreement among the respondents on the need to establish a culture of learning (node 21) and encourage employees to share knowledge and experience (node 16). Some of the interviewees came up with recommendations to achieve that by creating an environment where people are less risk-averse and more willing to share failures, especially considering that much of the learning comes from failure, which is inevitable in a complex world of projects. "This is precisely why learning from mistakes is so imperative" (Syed, 2015 , p.58). From the perspectives of the interviewees in order to create the risk-free environment that will encourage constructive criticism and will facilitate learning from failures, a leadership support is essential (nodes 37 and 30). Support and encouragement from the leadership directly contributes to improvement of IM and KM. 
One of the respondents mentioned that for the success of $\mathrm{KM}$ it is important to help leaders realise that lack of failures means that the organisation is too conservative (node 96) and is not flexible to constantly changing environments.

The lack of understanding the difference between data, information and KM is another issue raised by one of the respondents (node 98):

"Sticking all your documents on your company website is not knowledge management. That is data storage with some headings. That is not the same thing... People believe they have knowledge, but they have information."

Capitalising on people's knowledge is crucial for the company's performance (Bij et al., 2003). There is a growing understanding in the sector that organisations need to focus on human systems to share knowledge that resides in human minds (Blackman, 2005; Churchman, 1972; Polanyi, 1962).

There was an agreement amongst interviewees that organisational context shapes innovation (Table 3, node 9). The interviewees agreed that the culture of innovative thinking needs to be cultivated and sustained, rather than be driven through "super-heroes" (Table 3, node 9). The characteristics of organisational culture, including freedom and empowerment, were described by many interviewees as facilitators to "innovative thinking". Organisational culture was described as a supportive and helpful aspect in enabling creative inspiration and the taking of steps towards innovative practices. The cultural issues and need to be addressed to build the capabilities at organisational and project levels (e.g. Davies and Brady, 2000; Prencipe and Tell, 2001).

The respondents mentioned that in order to establish the culture of innovative thinking, among other actions, it is important to create a collaborative working environment (Table 3, node 42), cultivate a culture of learning (Table 3, node 21), establishing R\&D department (Figure 1, node 39), reduce control and encourage risk-taking (Figure 1, node 25) and 
celebrate innovation (node 129). Many interviewees contended that many construction innovations originate from the supply chain (e.g. suppliers, manufacturers and subcontractors). Those who shared this position argued that SMEs are more flexible and "innovative" in comparison to larger construction firms (Lu and Sexton, 2007). Overall, there was an agreement among the interviewees that work environment shapes innovation (Figure 1, node 42). The respondents especially emphasised the importance of sharing knowledge with the client (node 44), engagement between suppliers and contractors at early project stages (node 64), aligning objectives among all involved parties and taking a more holistic approach to how processes are engaged with one another (node 78). 


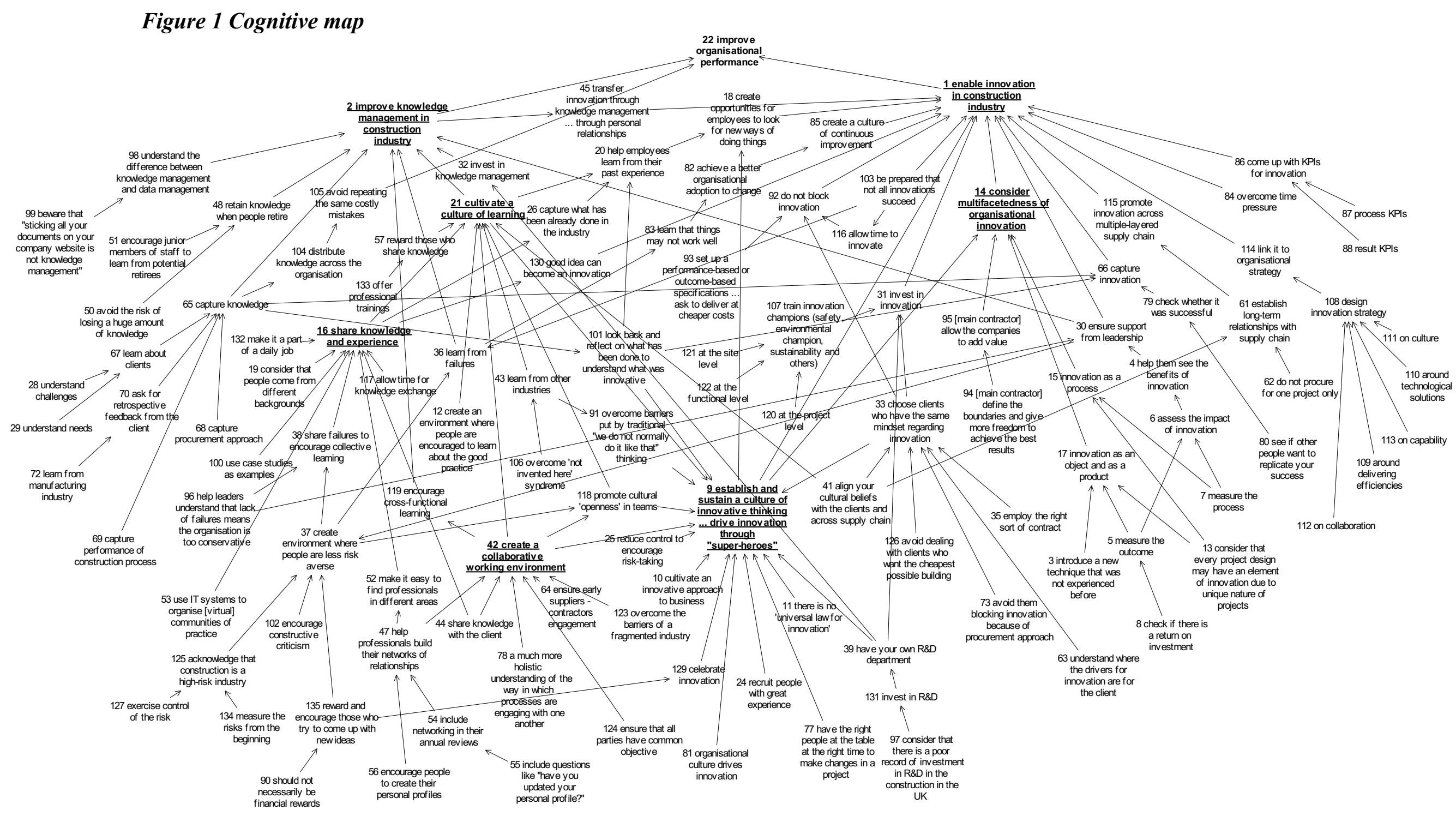


As a Property Services Director from an independent social business reflected:

"Work environment is really important because the culture of our organisation is very much about empowering people. My boss is the Chief Executive and his management is very much 'you can do what you want'. He does not interfere. That sort of empowers me to make a difference. That culture continues all the way up to our board. People in our board are 'pushers'; they are 'stretchers'; they are 'challengers'. That helps to push and drive an innovation. They are not asked for an innovation, but they are embraced. The whole culture if it works every way down then everyone will work towards the same goal."

Work atmosphere attributes, including empowerment and a freedom to pursue one's own interests, were described as incentives towards "innovative thinking". Organisational culture was viewed as a shared belief among each stakeholder that contributes to achieving organisational goals. The above argument was reinforced by the Design Manager from a civil engineering contractor firm who described the "king sheet pilling" project as an innovation:

"I regard myself not necessarily as being innovative, but certainly as a lateral thinker. And my line manager allowed me a freedom to pursue my ideas. I did not have day-to-day monitoring. If you are lucky to be in the culture of the organisation that is sort of hiring the individuals, allowing the individuals to pursue their own interest. You have to do your day jobs as well as pursuing your own interest. That is important for innovation to succeed."

A few interviewees expressed their views on innovation champions (Figure 1, node 107). They emphasised the importance of investing in training innovation champions on safety, environmental, sustainability and other key areas of the industry at different levels (site, functional and project). Of particular note is that the respondents often recognise other people as innovation champions, and not necessarily themselves. For example, the group innovation knowledge managers from a building contractor firm described a CEO as an innovation champion: 
"If people cannot 'innovate', then they would phone me and say: "This is not working". So, it is down to me then to work on those processes and change it and understand why the problem is. As a culture, you have got a prime person in the business as a "cultural leader" and a "champion". It goes to a chief executive board and our investors. Also it goes to people employed, down to their careers, down to their career development, training department. So, that is everyone's responsibility."

A significant percentage of interviewees contended that they worked in organisations which had a "culture of innovation" and collaboration with the supply chain. This tendency was articulated especially clearly by the manager from a building contractor firm who emphasised that the firm had a sort of own identity that he and others were especially proud of:

"In our DNA how we do stuff - to do things differently, to try and engage with whole supply chain, the whole design, the whole process to make sure that we deliver something that is innovative. We were proud of it; we have done it."

The above quotation demonstrates the perception of organisational identity as "innovative" by the interviewee. Many interviewees were positive in viewing their firms and the construction sector as a whole as "innovative" and that over the years the sector has improved in terms of learning from experiences (e.g. successful and failed innovations). The ways practicing mangers perceive and talk about their firms and the sector as a whole have important implications for forming organisational culture, identities and images (e.g. Gioia et al., 2000; Hatch and Schultz, 1997).

Establishing mutual understanding and trust within supplier networks has long been a central concern for the management and success of co-learning (Orange et al., 1999) and effective supply chain management (Love et al., 2004). As the map demonstrates, establishing long-term relations and aligning cultural beliefs with supply chain (nodes 41,61 ) 
promotes innovation across multi-layered supply chain (node 115), which eventually contributes to enabling innovation in the construction industry (node 1).

\section{Conclusions}

In this article we explored the ways innovation becomes enabled in PBFs through knowledge management and sharing. The construction is a complex industry with a wide range of enterprises starting from sole-traders, small and medium enterprises to multi-nationals working on construction projects in long supply chains. Construction projects are formed by the teams of professionals from different organisations across the long and complex supply chain, who generate a great deal of tacit knowledge. However, internal forces such as the delivery pressure, temporary nature, project's structure and management style promote functional efficiency at the expense of collaborative and innovative activities. The complexity of complexity of construction work requires a more holistic reflective approach to KM and IM with consideration of the interaction between the systems, procedures, workspace culture and the people in the organisation. This is consistent with authors such as Blayse and Manley (2004), Bossink (2004, 2018), Egbu (2004) and Maqsood and Finegan (2009) who have recognised the need for a holistic approach to better understanding of how to enable innovation in construction.

In this research, the importance of human values, shared beliefs and motivation for continuous learning and innovation at individual, team, project and firm levels were emphasised. Reflective practitioner perspective helps to makes sense of practitioners' perceptions on IM and $\mathrm{KM}$ and provides a basis for future actions. The interviewees acknowledged the value of the reflections on obtained past experiences that shape the ways they learn and innovate at present and in the future. The evidence shows that the industry needs robust KM systems and processes to enable continuous learning and innovation, which, however, requires a cultural shift from buck-passing and fear of blame to knowledge sharing 
and learning from success and equally from innovation failure. In large construction firms, knowledge is generated mainly outside the client and main contractor organisational boundaries and in order to motivate people to share operational knowledge stored in their minds, PBFs need to encourage social interaction based on trust and mutual understanding.IM and KM should be seen as systems for improving organisational and industrial performance. KM helps PBFs identify new, innovative knowledge internally and across its supply chain and incorporate it into the work practices. KM also enables innovation by suggesting processes that can help organisations to obtain, adjust and use external innovative knowledge.

The research findings demonstrate a lack of investment in stimulating knowledge and innovation, lack of leadership commitment and the over-reliance on individuals (innovation and knowledge champions) and teams to take responsibility for learning and sharing lessons learned. The previous research has only highlighted the important role of innovation champions (e.g. Blayse and Manley, 2005; Dulami et al., 2005; Egbu, 2004) but have not explored in detail their nature, both and formal and informal roles, and their communities and networks. The PBFs need more strategic approach to stimulating reflection on knowing-inpractice and learning from and between projects. IM and KM should be viewed as key leadership capabilities which require investment, robust processes and leadership support. Our research has contributed to the existing body of knowledge by effectively linking the disciplines of IM, KM and learning. It emphasises the importance of cultivating a culture of knowledge sharing and learning for enabling innovation in project-based environments. In this environment innovation and knowledge champions and their communities of practices and networks play an important role in collective actions towards continuous improvement and future innovations.

This research has important implications for practice. It provides a foundation for project practitioners to critically reflect on their KM, knowledge sharing and IM practices to cultivate a culture of learning and innovative thinking. By better understanding the ways organisational 
knowledge can be managed to become an enabler of innovation would allow to build and enhance firms' innovative capabilities and associated with it individual and team competencies. Considering the importance of KM and learning for innovation, the leadership of PBFs should take a leading role in cultivating a risk-free culture to foster inter- and intraproject collaboration and learning from successes and failures enhanced by reflection in- and on-action. A more transformational approach from the leaders of PBFs is required to facilitate individual and team learning in projects. It is well-known that construction innovations mainly originate from the supply chain, thus collaborative learning across projects can facilitate joint risk management, boost innovative thinking and contribute to effective problem solving. For IM and $\mathrm{KM}$ initiatives to be successful, they need to start by understanding and aligning the mental models of the senior managers. There is also a real need for innovation knowledge managers as formal job positions in the construction sector. Their role is in connecting innovation with knowledge and learning and contribute to the continuous improvement and innovative thinking culture of the construction sector.

This study prepared the ground for a more elaborate research on the impact of KM on IM in a project work context. More attention is merit to the social networks of innovation and knowledge managers and champions in project-based sectors. The job roles and professionalism of innovation knowledge managers needs further exploration. The researchers demonstrate that cognitive mapping technique is a useful tool in exploring the connection between IM and $\mathrm{KM}$ in greater detail, but other approaches and their combinations are welcome in future research.

\section{References}

Ackermann, F. \& Eden, C. (2010). Strategic options development and analysis. In M.

Reynolds and S. Holwell (Eds.), Systems approaches to managing change: A practical guide (pp. 135-190). London: Springer. 
Anumba, C. J., Egbu, C. \& Carillo, P. (2005). Knowledge management in construction. Oxford, UK: Blackwell Publishing.

Argyris, C. \& Schön, D. A. (1974). Theory in practice: increasing professional effectiveness. Oxford: Jossey-Bass.

Argyris, C. \& Schön, D. (1978). Organisational learning: A theory of action perspective. Reading, MA: Addison-Wesley.

Artto, K. \& Kujala, J. (2008). Project business as a research field. International Journal of Managing Projects in Business, 1(4), 469-497.

Ayas, K. \& Zeniuk, N. (2001). Project-based learning: Building communities of reflective practitioners. Management Learning, 32(1), 61-76.

Atkin, B. (1999). Innovation in the construction sector. Brussels: ECCREDI Study.

Bij, H., Song, X. \& Weggeman, M. (2003). An empirical investigation into the antecedents of knowledge dissemination at the strategic business unit level. Journal of Product Innovation Management, 20(2), 163-179.

Barbaroux, P., Attour, A. \& Schenk, E. (2016). Knowledge management and innovation: Interaction, collaboration, openness. London: ISTE Ltd.

Barlow, J. (2000). Innovation and learning in complex offshore construction projects. Research Policy, 29(7-8), 973-989.

Blackman, D.A. (2005). The role of mental models in the development of knowledge management systems. International Journal of Organisational Behaviour, 10(6), 757769.

Blayse, A.M. \& Manley, K. (2004). Key influences on construction. Construction Innovation: Information, Process, Management, 4(3), pp. 143-154. 
Bossink, B.A.G. (2004). Managing drivers of innovation in construction networks. Journal of Construction Engineering and Management, 130(3), 449-454.

Bossink, B.A.G. (2018). The influence of knowledge flow on sustainable innovation in a project-based industry: from demonstration to limited adoption of eco-innovations. Journal of Cleaner Production, 193, 249-262.

Carrillo, P.M., Anumba, C.J. \& Kamara, J. M. (2000). Knowledge management strategy for construction key IT and contextual issues. Construction Informatics Digital Library http://itc.scix.net/paper w78-2000- 155.content.

Carrillo, P.M. (2004). Managing knowledge: lessons from the oil and gas sector. Construction Management and Economics, 22(6), 631-642.

Carrillo, P.M., Ruikar, K. \& Fuller, P. (2013). When will we learn? Improving lessons learned practice in construction. International Journal of Project Management, 31(6), $567-578$.

Castro, A.L., Yepes, V., Pellicer, E. \& Cuellar, A.J. (2012), Knowledge management in the construction industry: state of the art and trends in research. Revista de la Construcción, 11(3), 62-73.

Churchman, C.W. (1972). The design of inquiring system: Basic concepts of systems and organization. NY: Basic Books.

Dave, B. \& Koskela, L. (2009). Collaborative knowledge management - A construction case study. Automation in Construction, 18(7), 894-902.

Davenport, T.H. \& Prusak, L. (1998). Working knowledge how organizations manage what they know. Boston: Harvard Business School Press. 
Davies, A. \& Brady, T. (2000). Organisational capabilities and learning in complex product systems: Towards repeatable solutions. Research Policy, 29(7-8), 931-953.

Davies, A., Gann, D. \& Douglas, T. (2009). Innovation in megaprojects: systems integration at London Heathrow Terminal 5. California Management Review, 51(2), 101-125.

Davies, A., Dodgson, M., Gann, D.M. \& MacAulay, S. (2017). Five rules for managing large, complex projects. MIT Sloan Management Review, 59(1), 73-78.

Dewey, J. (1910). How we think. Boston, D.C: Heath.

De Long, D. \& Fahey, L. (2000). Diagnosing cultural barriers to knowledge management. Academy of Management Perspectives, 14(4), 113-127.

Du Plessis, M. (2007). The role of knowledge management in innovation. Journal of Knowledge Management, 11(4), 20-29.

Dulami, M.F., Nepal, M.P. \& Park, M. (2005). A hierarchical structural model of assessing innovation and project performance. Construction Management and Economics, 23(6), $565-577$.

Duryan, M. \& Smyth, H. (2019a). Cultivating sustainable communities of practice within hierarchical bureaucracies: The crucial role of an executive sponsorship. International Journal of Managing Projects in Business, 12(2), 400-422.

Duryan, M. \& Smyth, H. J. (2019b). Service design and knowledge management in the construction supply chain for an infrastructure programme. Built Environment Project and Asset Management, 9(1), 118-137.

Eden, C. (2004). Analyzing cognitive maps to help structure issues or problems. European Journal of Operational Research, 159(3), 673-686. 
Eden, C. \& Ackermann, F. (1998). Making strategy: The journey of strategic management. London: Sage Publications.

Egbu, C.O. (2004). Managing knowledge and intellectual capital for improved organizational innovations in the construction industry: An examination of critical success factors. Engineering, Construction and Architectural Management, 11(5), 301-315.

Flyvbjerg, B., Skamris Holm, M. \& Buhl, S. (2002). Underestimating costs in public works projects - Error or lie? Journal of the American Planning Association, 68(3), 279-295.

Gann, D.M. \& Salter, A.J. (1998). Learning and innovation management in project-based, service-enhanced firms. International Journal of Innovation Management, 2(4), 431-454.

Gann, D.M. \& Salter, A.J. (2000). Innovation in project-based, service-enhanced firms: the construction of complex products and systems. Research Policy, 29, 955-72.

Gioia, D.A., Schultz, M. \& Corley, K.G. (2000). Organizational identity, image, and adaptive instability. The Academy of Management Review, 25(1), 63-81.

Hartmann, A. (2006). The context of innovation management in construction. Construction Management and Economics, 24(6), 567-578.

Hatch, M.J. \& Schultz, M. (1997). Relations between organizational culture, identity and image. European Journal of Marketing, 31(5/6), 356-365.

Hertogh, M., Baker, S., Staal-Ong, P.L. \& Westerveld, E. (2008). Managing large infrastructure projects: Research on best practices and lessons learnt in large infrastructure projects in Europe. Baarn: AT Osborne BV.

Hobday, M. (2000). The project-based organization: An ideal form for managing complex products and systems. Research Policy, 29(7-8), 871-893.

Kelly, G.A. (1991). The psychology of personal constructs. NY: Norton. 
Kelly, N., Edkins, A.J., Smyth, H.J. \& Konstantinou, E. (2013). Reinventing the role of the project manager in mobilising knowledge in construction. International Journal of Managing Projects in Business, 6(4), 654-673.

Lave, J. \& Wenger, E. (1991). Situated learning: Legitimate peripheral participation. Cambridge, UK: Cambridge University Press.

Love, P.E., Irani, Z. \& Edwards, D.J. (2004). A seamless supply chain management model for construction. Supply Chain Management: An International Journal, 9(1), 43 - 56.

Love, P.E., Fong, P.S.W. \& Irani, Z. (2005). Management of knowledge in project environments. London: Routledge.

Lu, S.-L. \& Sexton, M. (2007). Innovation in small construction knowledge-intensive professional service firms: A case study of an architectural practice. Construction Management and Economics, 24(12), 1269-1282.

Maqsood, T. \& Finegan, A.D. (2009). A knowledge management approach to innovation and learning in the construction industry. International Journal of Managing Projects in Business, 2(2), 297-307.

McKinsey Global Institute (2017). Reinventing construction: A route to higher productivity. McKinsey \& Company.

Newell, S., Bresnen, M., Edelman, L., Scarbrough, H. \& Swan, J. (2006). Sharing knowledge across projects: Limits to ICT-led project review practice. Management Learning, 37(2), 67-185.

Newell, S., Robertson, M., Scarbrough, H. \& Swan, J. (2009). Managing knowledge work and innovation. London: Pelgrave Macmillan. 
Nonaka, I. \& Takeuchi, H. (1995). The knowledge creating company: How Japanese companies create the dynamics of innovation. NY: Oxford University Press.

Oeij, P.R.A., Gaspersz, J.B.R., van Vuuren, T. \& Dhondt, S. (2017). Leadership in innovation projects: An illustration of the reflective practitioner and the relation to organizational learning. Journal of Innovation and Entrepreneurship, 6(2), 1-20.

Orange, G., Cushman, M. \& Burke, A. (1999). COLA: a cross-organisational approach within UK industry. 4th International Conference on Networking Entities, Krems, Austria.

Payne, J., Roden, E. \& Simister, S. (2019). Managing knowledge in project environments. NY: Routledge.

Polanyi, M. (1962). Personal knowledge: Toward a post critical philosophy. NY: Harper Torchbooks.

Polanyi, M. (1967). The tacit dimension. London: Routledge and Keoan Paul.

Prahalad, C.K. \& Ramaswamy, V. (2003). The new frontier of experience innovation. MIT Sloan Management Review, 44(4), 12-18.

Prencipe, A. \& Tell, F. (2001). Inter-project learning processes and outcomes of knowledge codification in project-based firms. Research Policy, 30(9), 1373-1394.

Ruggles, R. (1998). The state of the notion: knowledge management in practice. California Management Review, 40(3), 80-89.

Ruoslahti, H. (2020). Complexity in project co-creation of knowledge for innovation. Journal of Innovation \& Knowledge, 5(4), 228-235.

Schön, D.A. (1983). The reflective practitioner: How professionals think in action. NY: Basic Books. 
Saunila, M. (2019). Innovation capability in SMEs: A systematic review of the literature. Journal of Innovation \& Knowledge, 5(4), 260-265.

Szulanski, G. (2000). The process of knowledge transfer: a diachronic analysis of stickiness. Organizational Behavior and Human Decision Processes, 82(1), 9-27.

Syed, M. (2015). Black box thinking: Marginal gains and the secrets of high performance: The surprising truth about success. Edinburg, Scotland: John Murray.

Train, A., Egbu, C.O. \& Hicks, J. (2006). Key issues in innovation and knowledge management in the finance and construction sectors. In D. Boyd (Ed.) Procs 22nd Annual ARCOM Conference, 4-6 September 2006, Birmingham, UK, Association of Researchers in Construction Management, pp. 1003-1013.

Turner, J.R. \& Keegan, A. (2001). Mechanisms of governance in the project-based organization: Roles of the broker and steward. European Management Journal, 19(3), 254-267.

Van de Ven, A.H. (1986). Central problems in the management of innovation. Management Science, 32(5), 590-607.

Van de Ven, A.H. (2017). The innovation journey: You can’t control it, but you can learn to maneuver it. Innovation, 19(1), 39-42.

Van de Ven, A.H., Polley, D., Garud, R. \& Venkataraman, S. (2008). The innovation journey. NY: Oxford University Press.

Walker, D.H.T. (2016). Reflecting on 10 years of focus on innovation, organizational learning and knowledge management literature in a construction project management context. Construction Innovation: Information, Process, Management, 16(2), 114-126. 
Winch, G.M. (2014). Three domains of project organizing. International Journal of Project Management, 32(5), 721-731. 